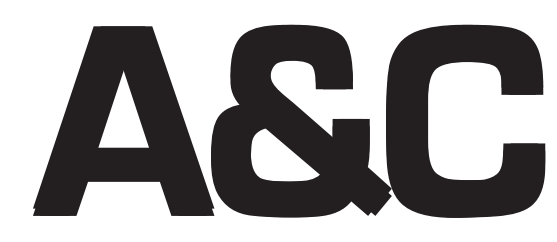

Revista de Direito Administrativo \& Constitucional

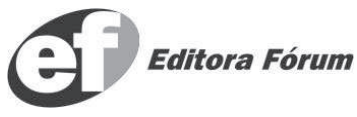

ISSN 1516-3210 


\section{A\&C REVISTA DE DIREITO ADMINISTRATIVO \& CONSTITUCIONAL}

\section{IPDA}

Instituto Paranaense

de Direito Administrativo

Direção Geral

Romeu Felipe Bacellar Filho

Direção Editorial

Paulo Roberto Ferreira Motta

Direção Executiva

Emerson Gabardo

Conselho de Redação

Edgar Chiuratto Guimarães

Adriana da Costa Ricardo Schier

Célio Heitor Guimarães

\section{Conselho Editorial}

Adilson Abreu Dallari (Brasil) Alice Gonzales Borges (Brasil) Antonello Tarzia (Itália)

Carlos Ari Sundfeld (Brasil)

Carlos Ayres Britto (Brasil)

Carlos Delpiazzo (Uruguai)

Cármen Lúcia Antunes Rocha (Brasil)

Celso Antônio Bandeira de Mello

(Brasil)

Clèmerson Merlin Clève (Brasil)

Clovis Beznos (Brasil)

Enrique Silva Cimma (Chile)

Eros Roberto Grau (Brasil)

Fabrício Motta (Brasil)

Guilhermo Andrés Muñoz - in memoriam

(Argentina)

Jaime Rodríguez-Arana Muñoz (Espanha)

Jorge Luís Salomoni - in memoriam
(Argentina)
José Carlos Abraão (Brasil)
José Eduardo Martins Cardoso (Brasil)
José Luís Said (Argentina)
José Mario Serrate Paz (Uruguai)
Juan Pablo Cajarville Peruffo (Uruguai)
Juarez Freitas (Brasil)
Julio Rodolfo Comadira - in memoriam
(Argentina)
Luís Enrique Chase Plate (Paraguai)
Lúcia Valle Figueiredo (Brasil)
Manoel de Oliveira Franco Sobrinho -
in memoriam (Brasil)
Marçal Justen Filho (Brasil)
Marcelo Figueiredo (Brasil)

\author{
Maria Cristina Cesar de Oliveira (Brasil) \\ Nelson Figueiredo (Brasil) \\ Odilon Borges Junior (Brasil) \\ Pascual Caiella (Argentina) \\ Paulo Eduardo Garrido Modesto (Brasil) \\ Paulo Henrique Blasi (Brasil) \\ Paulo Neves de Carvalho - in memoriam \\ (Brasil) \\ Paulo Ricardo Schier (Brasil) \\ Pedro Paulo de Almeida Dutra (Brasil) \\ Regina Maria Macedo Nery Ferrari (Brasil) \\ Rogério Gesta Leal (Brasil) \\ Rolando Pantoja Bauzá (Chile) \\ Sérgio Ferraz (Brasil) \\ Valmir Pontes Filho (Brasil) \\ Weida Zancaner (Brasil) \\ Yara Stropa (Brasil)
}

A246 A\&C Revista de Direito Administrativo \& Constitucional. ano 3, n. 11, jan./mar. 2003. Belo Horizonte: Fórum, 2003.

Trimestral

ano 1, n. 1, 1999 até ano 2, n. 10, 2002 publicada pela Editora Juruá em Curitiba

ISSN 1516-3210

1. Direito Administrativo. 2. Direito Constitucional. I. Fórum.

CDD: 342

CDU: 33.342

(C) 2008 Editora Fórum Ltda.

Todos os direitos reservados. É proibida a reprodução total ou parcial, de qualquer forma ou por qualquer meio eletrônico ou mecânico, inclusive através de processos xerográficos, de fotocópias ou de gravação, sem permissão por escrito do possuidor dos direitos de cópias (Lei nº 9.610, de 19.02.1998).

Editora Fórum Ltda

Editor responsável: Luís Cláudio Rodrigues Ferreira

Av. Afonso Pena, 2770 - 15\%16ªndar - Funcionários

CEP 30130-007 - Belo Horizonte/MG - Brasil

Coordenação editorial: Olga M. A. Sousa

Tel.: 08007043737

Internet: www.editoraforum.com.br

Pesquisa jurídica: Fátima Ribeiro - OAB/MG 74868

Revisora: Lourdes Nascimento

Projeto gráfico e diagramação: Luis Alberto Pimenta

e-mail: editoraforum@editoraforum.com.br

Bibliotecária: Fernanda de Paula Moreira - CRB 2900 - 6a região

Esta publicação está indexada no Ulrich's Periodicals Directory

Os conceitos e opiniões expressas nos trabalhos assinados são de responsabilidade exclusiva de seus autores.

Impressa no Brasil / Printed in Brazil

Distribuída em todo o Território Nacional 


\title{
Densificações democráticas do serviço público no Brasil: alguns pressupostos ${ }^{1}$
}

Rogério Gesta Leal

Desembargador do Tribunal de Justiça do Estado do Rio Grande do Sul. Doutor em Direito. Professor Titular da Universidade de Santa Cruz do Sul. Professor Colaborador da Universidade Estácio de Sá. Professor Visitante da Università Túlio Ascarelli - Roma Trè, Universidad de La Coruña - Espanha e Universidad de Buenos Aires.

\begin{abstract}
Resumo: O presente artigo aborda o serviço público no âmbito do Estado Democrático. Inicialmente analisa-se o perfil do Estado desde a crise do Petróleo de 1929 até o Estado hodierno, inclusive no Brasil, demonstrando a mudança da Administração Pública burocrática para a gerencial. Em seguida é proposta uma forma de gestão pública comunicativa frente ao novo modelo de Estado e dos serviços públicos. Citam-se vários autores e suas idéias acerca da responsabilidade social de todos os cidadãos e do Estado Providência. Pautam-se alguns pressupostos básicos para a formatação de políticas públicas e ações materiais que envolvam especialmente os serviços públicos. Afirmase que resta à sociedade avaliar os resultados das ações e políticas públicas. Abordam-se questões que são necessárias para que a Administração Pública se configure democrática e comunicativa. Por fim, sustenta-se que, no novo modelo de gestão pública compartida, devem ser criadas as condições objetivas e subjetivas para que a participação política da cidadania seja condição de possibilidade da Administração Pública Democrática de Direito.
\end{abstract}

Palavras-chave: Estado Democrático. Administração Pública. Burocracia. Administração gerencial. Serviços públicos. Estado Providência. Ações e políticas públicas.

Sumário: 1 Notas introdutórias - 2 Apogeu e queda do Estado de BemEstar Social: a necessidade de aprender com história - 3 Qual o papel da cidadania em face dos serviços públicos? - 4 A formatação dos serviços públicos como resultado da interlocução entre Estado e sociedade - Referências

\section{Notas introdutórias}

Pretendo desenvolver neste ensaio a questão que envolve a morfologia do serviço público no âmbito de um Estado que o presta com uma perspectiva de promovedor do bem-estar da comunidade e os limites desta concepção em face do paradoxo existente entre finitude de receitas e infinitude de demandas. Para tanto, vou delimitar o perfil do Estado de BemEstar dos anos 1970/1990, notadamente na Europa Central, e a forma

\footnotetext{
Este trabalho foi desenvolvido por conta do projeto de pesquisa intitulado $A$ delegação da prestação de serviços públicos a agentes privados e sua regulação pelo poder público: modelos, fundamentos e conteúdos numa perspectiva comunitária e da cidadania, junto ao Centro de Estudos e Pesquisas de Energias Alternativas e Serviços Públicos, do Programa de Mestrado em Direito da Universidade de Santa Cruz do Sul — UNISC, RS, Brasil.
}

A\&C R. de Dir. Administrativo \& Constitucional, Belo Horizonte, ano 8, n. 33, p. 91-113, jul./set. 2008 
com que ele enfrenta o tema dos serviços públicos, para, a partir daí, verificar de que maneira este modelo forja um tipo de relação com a sociedade civil e como superá-la, para além de uma relação meramente de fornecedor e consumidor.

\section{Apogeu e queda do Estado de Bem-Estar Social: a necessidade de aprender com história}

É inafastável que, desde a crise do petróleo de 1929 e até a década de 1970, forjou-se, notadamente em nível de Europa Central — no mínimo e de forma mais explícita - um verdadeiro pacto social entre capital e trabalho, não suficiente para abalar o projeto de uma economia de mercado capitalista e concentradora de renda, mas que facilitou de forma muito destacada a paz social no âmbito da produção e mudanças para a melhora das condições econômicas e sociais que elevaram o nível de vida da população em geral. Quero dizer que, ao lado do crescimento econômico das elites sociais, pode-se perceber o surgimento de políticas distributivas que nivelaram mais as rendas entre os que mais tinham e os que menos tinham — persistindo até hoje de forma mais mitigada tal equação. ${ }^{2}$

Sem sombra de dúvidas que é na Europa Central que se vai encontrar um maior e mais variado número de experiências neste sentido, todas operando a partir de um sistema de proteção social e ações de apoio prestadas pelo Estado aos cidadãos para limitar os riscos à vida e os danos produzidos pelo mercado; afigura-se o Estado, em verdade, como verdadeiro mecanismo de segurança de uma sociedade caracterizada pelo desenvolvimento da indústria, de uma perspectiva de pleno emprego e pela elaboração de políticas sociais baseadas em um sistema contributivo garantido pela plena ocupação. ${ }^{3}$

\footnotetext{
2 Por certo que, detrás disto, pode-se encontrar uma explícita intenção de apresentar uma contra-proposta ao comunismo do Leste Europeu, derrocando suas promessas de igualitarismo social. Neste sentido, ver o texto de NAVARRO. Neoliberalismo y Estado del Bienestar.

3 A despeito da advertência que faz Krell, no sentido de que vários autores alemães se dirigem contra direitos fundamentais sociais na Constituição porque estes seriam, na sua maioria, não-realizáveis na atualidade por parte do Estado, provocando a impressão ao cidadão de que todo o texto constitucional seria nada mais do que uma "construção de frases" ou um "catecismo popular, cheio de utopias" que resultaria na perda da normatividade da Carta e da sua força de estabelecer valores. KRELL. Realização dos direitos fundamentais sociais mediante controle judicial da prestação dos serviços públicos básicos (uma visão comparativa). Revista de Informação Legislativa, p. 244. Ver o texto de PACI. Welfare State: chi há beneficitato dello Stato Sociale, a chi andrà la nuova solidarietà, p. 49 e seguintes. Da mesma forma o OFFE. Contradicciones en el Estado del Bienestar, p. 110, quando assevera que o modelo de Estado de Bem-Estar europeu, em seus umbrais, garantiza unos niveles de vida mínimos y unos servicios sociales universales, pero el objetivo del pleno empleo acabaría como expresión de la proximidad existente entre la economia y la política, bajo el domínio del Estado, que había salido fortalecido de la imposibilidad de autorregulación del mercado (Gran Depresión y fin del liberalismo econômico).
}

A\&C R. de Dir. Administrativo \& Constitucional, Belo Horizonte, ano 8, n. 33, p. 91-113, jul./set. 2008 
Ocorre que, em uma situação social em que estes pressupostos ou elementos não ocorrem, ou deixam de ocorrer (situação que se dá a partir da década de 1970), o grande desafio é passar de um Welfare assistencial a um Welfare de oportunidades e de responsabilidades individuais, no qual os novos princípios regedores deste cenário são: individualismo responsável, universalismo do Estado e coesão social. Na dicção de Cachón:

El valor de la libertad se sustenta en la idea de que es necesario dar a todos los ciudadanos iguales oportunidades, confiando una posición contra los riesgos de la vida: el individuo debe poder decidir libremente los instrumentos que tiene que utilizar para configurar su seguridad. Sin embargo, la igualdad de los ciudadanos debe garantizarse universalmente por el Estado, mientras que la fraternidad o cohesión social (término preferido al de solidariedad) representa el nuevo pacto social, el elemento de cohesión y de identidad colectiva. $^{4}$

Por certo que este universalismo estatal encontrou logo limitações severas ao longo do tempo, em especial no que tange às suas três dimensões, a saber, (1) acesso universal, (2) não condicionado e (3) a todas as pessoas. A doutrina especializada tem insistido com o fato de que o primeiro aspecto precisa ser garantido, todavia, os demais necessitam de limitações, inclusive em face da própria natureza constitutiva das demandas e suas múltiplas variáveis. Ashford lembra que não se pode, em nome das garantias e prerrogativas asseguradas pela ordem constitucional e pública do Estado Democrático de Direito, imunizar ou mesmo isentar a cidadania de suas quotasparte, haja vista que, por exemplo, compete também ao núcleo mais fundante e tradicional da enucleação humana - a família - competências no que tange ao campo de realización de três grandes objetivos: valorar las actividades de asistencia; combatir la discriminación de gênero; combatir y reducir la eclusión social. ${ }^{5}$ Não só isto, mas as promessas constitucionais em uma República correspondem, inevitavelmente, no sólo al Estado, sino a la Iglesia, a la familia,

\footnotetext{
4 CACHÓN. Estado de Bienestar y Capitalismo Avanzado, p. 111. Aqui vale também a lembrança de HABERMAS. Teoria dell'agire comunicativo, p. 1014-1015, no sentido de que Si lo Stato Sociale tutela l'individuo come lavoratore e ne potenzia il ruolo di consumatore, allo stesso tempo il ruolo di cliente delle prestazioni dell'apparato pubblico cresce in modo ipertrofico, a scapire del ruolo di cittadino inteso come attivo titolare della sovranità politica. Esta intervenção metodologicamente desmesurada do Estado Social Assistencialista, cada vez mais monetarizada e burocratizada, si configurano come una sorta di colonizzazione, che lede la sostanza comunicativa della lebenswelt inducendo effetti patologici. Importa dizer que Habermas reconhece a importância do Estado Social em determinados momentos e circunstâncias históricas, todavia, ele não é suficiente, per se, para os fins de restituire senso e identità alle storie di vita degli individui che diventano oggeto di assistenza.

5 ASHFORD. La aparición de los Estados de Bienestar, p. 119.
} 
a las organizaciones del Tercer Sector e, incluso, al próprio mercado. Cada actor posee modalidades próprias de acción. ${ }^{6}$

É desta compreensão mais alargada das funções públicas e dos direitos e garantias fundamentais que se vai chegar a propor um tipo de Welfare Mix, no sentido de compartir com todo o tecido social e seus atores institucionais ou não - a concepção, formatação, execução e avaliação das competências estatais e os seus destinatários, haja vista as profundas diferenças existentes em matrizes distintas de história e conjuntura de cada país, região, etc.

Independentemente dos cenários referidos, em qualquer deles, o Estado, enquanto instituição política e jurídica, deverá equalizar suas forças e competências junto e através da cidadania que representa, sob pena de criar condições de inviabilização dos seus próprios objetivos. Em outras palavras, mister é que se permita na gestão de políticas públicas (e dos próprios serviços públicos) activar las energías de los ciudadanos, y, al mismo tiempo, en un buen sistema de solidaridad redistributivo que remarque la solidaridad inter e intrageneracional. ${ }^{7}$

A despeito da derrocada da matriz mais assistencialista do Estado de Bem-Estar, e de seus serviços de inclusão social, também alguns postulados de ordem pública ele tem constituído ao longo do tempo, nos legando, por exemplo, a idéia de que as políticas públicas sociais devem corrigir as desigualdades de recursos e condições dignas de vida herdadas do capitalismo industrial e pós-industrial, criando condições efetivas para que os indivíduos possam expressar e desenvolver todas as suas potencialidades, e mesmo criando possibilidades materiais e cognitivas para que eles possam constituí-las.

Este cenário, todavia, não foi capaz de eliminar as zonas de pobreza que foram se forjando pelo processo de desenvolvimento humano e social desequilibrado, gerando, por sua vez, índices de exclusão violentos que vão se fazer sentir — notadamente - nas estruturas urbanas consolidadas decorrentes ora da industrialização desenfreada, ora do empobrecimento do campo. ${ }^{8}$ Em face disto, impõe-se ao Poder Público realizar intervenções

\footnotetext{
6 Idem, p. 125. É interessante verificar como o autor identifica o fato de que desde mediados de los setenta encontramos las primeras señales de crisis: estancamiento económico, fin del pleno empleo, crisis fiscal y disminución de los recursos presupostarios, así como la pérdida de confianza en el proprio sistema, al ponerse en duda la eficiencia y capacidad de los mecanismos de bienestar, cuestionándose la legitimidad del próprio sistema del Estado de Bienestar keynesiano.

7 ALEMÁN. Fundamentos de Bienestar Social, p. 71.

8 Ver meu texto LEAL. A função social da cidade e da propriedade no Brasil.
}

A\&C R. de Dir. Administrativo \& Constitucional, Belo Horizonte, ano 8, n. 33, p. 91-113, jul./set. 2008 
compensatórias aportando recursos orçamentários e políticas públicas corretivas de algumas destas situações. Quando não o faz, agudiza ainda mais o processo de fragilização da ordem social, das instituições democráticas e da legitimação do processo de gestão pública existente.

E efetivamente pode-se visualizar neste período um exercício de poder político-institucional preocupado e compromissado com direitos sociais e coletivos, visando exatamente constituir condições mínimas de convivência e desenvolvimento entre interesses e demandas distintas, marcados por políticas econômicas keynesianas de bem-estar, isto ao menos até a década de 1970, quando o Ocidente vai assistir, como um todo, a uma mudança brusca de paradigma estatal e governamental, fundado em matrizes chamadas neoliberais, cujos grandes postulados podem assim ser alinhados:

(1) A necessidade de uma reforma da política fiscal dos Estados Nacionais, em busca de orçamentos equilibrados, no sentido de diminuir a dívida pública, evitando tensões inflacionárias que levassem a uma retroalimentação do déficit da Fazenda;

(2) A necessidade decorrente de se fazer uma profunda revisão da despesa pública em geral, a começar pelas políticas de subvenções sociais e atinentes à redistribuição de renda, freando desta forma a intervenção exacerbada do Estado em searas próprias da iniciativa privada; ${ }^{9}$

(3) A necessidade de se reduzir a carga tributária com o objetivo de liberar mais recursos ao setor privado, eis que mola propulsora dos mercados já internacionalizados (o que implica política monetária restritiva);

(4) A necessidade de se forjar uma política comercial e fiscal liberalizadora de todo o tipo de controle e barreiras, incluídos aí os movimentos de capitais financeiros; ${ }^{10}$

(5) A necessidade de se fazer uma profunda revisão sobre os níveis extremos de estatização de iniciativas econômicas, visando privatização e terceirização, movimentando assim o mercado.

Como quer De Loernardis, as conseqüências sociais desta política neoliberal são evidentes e têm uma materialização desigual segundo as

\footnotetext{
9 Estou falando aqui de cortes profundos de políticas compensatórias e algumas até assistenciais, envolvendo desemprego, saúde, educação, seguridade social, etc.

10 Uma nota muito explícita disto é a desregulação das relações de trabalho, por exemplo.
}

A\&C R. de Dir. Administrativo \& Constitucional, Belo Horizonte, ano 8, n. 33, p. 91-113, jul./set. 2008 
políticas concretas de cada governo, cabendo destacar, dentre outros aspectos restritivos, a eliminação do salário indireto através de cortes e reduções no ensino público, defesa do meio ambiente, transporte coletivo, etc. ${ }^{11}$ Ora, quais as razões de justificação e de fundamentação deste modelo de Estado e Governo Mínimos? Por certo de que tantas tarefas ao Estado do Bem-Estar estariam sobrecarregando os governos e os orçamentos públicos de tal forma a gerar situações de absoluta ingovernabilidade, afigurando-se imperioso libertar o Estado de tamanha carga e responsabilidade institucional. Deveria, pois, este Estado, reduzir-se ao trato de segurança e proteção da ordem estabelecida por uma economia livre, assegurando as relações contratuais e os pactos estabelecidos.

Este modelo não subsistiu aos desafios e problemas que ele próprio agravou, que foi a fragilização ainda maior de camadas inteiras da população, secundado por um Estado Absenteísta, quando, na verdade, deveria ter se mantido fiel à idéia da social-democracia instituidora do bem-estar da comunidade garantido pelas instituições estatais. Como quer Ralph Dahrendorf, junto a los efectos de la globalización debemos considerar un amplio abanico de decisiones, de gran relieve para los individuos, que continúan siendo tomados por los Estados-Nación. Me refiero sobre todo a la rama de cuestiones que podríamos definir como política social: educación, pensiones, asistencia, bienestar social. ${ }^{12}$

É certo que esta nova configuração de forças internacionais e globalizadas está a impor desafios a todos os setores sociais, em especial à Administração Pública, que agora já não pode mais tratar o interesse público

\footnotetext{
11 DE LEONARDIS. In un diverso Welfare: sogni ed incumbi, p. 51. Na mesma direção ver o texto de BECK. Vivir nuestra propria vida en un mundo desbocado: individuación, globalización y política. In: GIDDENS; HUTTON. En el límite: la vida en el capitalismo global. Ainda é de se destacar o informe da histórica Comissão Trilateral, formada por Estados Unidos, Europa Ocidental e Japão, na década de 1970, e seu documento intitulado The Governability of Democracies, publicado em 1975, dando conta do fato de que as pessoas em geral, uma vez liberadas de vínculos tradicionais de obediência e de valores tradicionais, começam a apresentar ao Estado demandas tamanhas que se produz uma sobrecarga de insumos tal que este não consegue responder - o que atinge de forma direta as obrigações corriqueiras e históricas que o Estado deveria manter em relação à sociedade (segurança pública, educação, infra-estrutura urbana e industrial, etc.). Participaram desta comissão, dentre outros, teóricos como Michel Crozier (Europa) e Samuel P. Huntington (EUA).

12 DAHRENDORF. Después de la Democracia, p. 115. Adreas Krell lembra que o modelo de Estado Social vigente na Alemanha de hoje tem como pontos básicos a industrialização, a tecnologia, a comunicação e a racionalidade na gestão dos serviços públicos. O Estado não é chamado somente para preservar e proteger o funcionamento livre da ordem econômica, mas para desenhar e planejar a vida social e o futuro da sociedade como um todo. Esse tipo de Estado Social já ultrapassa, nas suas finalidades e pretensões, o modelo do clássico Welfare State e procura a harmonia entre, de um lado, idéias liberais de uma economia livre e, de outro, a igualdade de chances e a distribuição de riquezas. Nesse contexto, vem se tornando uma tarefa essencial a progressiva "prevenção de riscos" (Risikovorsorge): o Estado tenta nortear e direcionar o processo de desenvolvimento científico-tecnológico da sociedade, protegendo-a contra as possíveis conseqüências perniciosas de fenômenos como a manipulação genética, a alteração de ecossistemas, doenças novas, a energia nuclear, etc. In: KRELL. Controle judicial dos serviços públicos básicos na base dos direitos fundamentais sociais. Revista de Informação Legislativa, p. 248.
}

A\&C R. de Dir. Administrativo \& Constitucional, Belo Horizonte, ano 8, n. 33, p. 91-113, jul./set. 2008 
como algo que lhe pertence de forma exclusiva e técnica, mas alberga em seu conceito mesmo níveis de complexidade e diferenciação demasiadamente grandes, impondo um gestar em redes de colaboração/interação significativas, envolvendo múltiplos níveis de governo, de administrações, de atores políticos os mais diversos. ${ }^{13}$

O Estado hodierno (notadamente no Brasil), em tais condições, passa a ter uma revigorada função de ordenação do caos e da agudizante exclusão social cometida por aquele modelo de organização produtiva, agora potencializada pelos termos dos vínculos políticos delimitados pelas diretrizes constitucionais — em especial as do Texto Político de 1988 — , tendo por tarefa e principal característica revitalizada a administração dos conflitos que perpassam a sociedade multicultural e tensa que o institui. Assim, um processo de democratização é, necessariamente, também um processo de organização do Estado, em que ele se mobiliza tendo em vista propiciar a possibilidade de prevenção e resolução dos conflitos existentes, bem como o atendimento das demandas individuais e coletivas, o que implica a constituição de processos e procedimentos adequados para tanto.

Veja-se que não deixo de reconhecer aqui, em termos de serviços públicos, que em alguns casos inexiste dúvida quanto à natureza pública ou privada de uma atividade, mas, diante da mudança de orientação política e econômica, é cada vez maior o número de casos em que não se encontram alguns dos traços característicos do serviço público em determinadas situações concretas, muito embora se lhes aplique o regime peculiar, ou viceversa. De outro lado, diante da intervenção das agências reguladoras e do Código de Defesa do Consumidor, por exemplo, mesmo nas situações em que os serviços públicos são prestados pela iniciativa privada, há uma nítida proteção do usuário por regras cogentes e protetivas destes. ${ }^{14}$

Por certo que estes processos e procedimentos estão longe de serem alcançados no Brasil, ao menos diante da histórica experiência

\footnotetext{
13 O que está a impactar inclusive o clássico conceito de serviço público forjado por León Duguit, na França do final do século XIX, no sentido de configurá-lo como toda atividade cuja realização é assegurada, regulada e controlada pelos governantes, por ser indispensável à realização e ao desenvolvimento da interdependência social, não podendo ocorrer sem a intervenção da força governamental (grifo pessoal). Ver o texto de DUGUIT. Les Transformations du Droit Public, p. 117 et seq. Da mesma forma no Brasil, MEIRELLES. Direito administrativo brasileiro, p. 119, sustentava que serviço público era todo aquele prestado pela Administração ou por seus delegados, sob normas e controle estatais, para satisfazer necessidades essenciais ou secundárias da coletividade ou simples convivência do Estado.

${ }^{14}$ Não posso avançar esta discussão aqui, por falta de espaço, todavia estou me referindo à tendência internacional de ações associadas da iniciativa pública para com a privada, gerando processos não de privatização do público, mas de descentralização dos serviços públicos, permitindo que alguns sejam ofertados pelo mercado, com regulação administrativa em todos os aspectos. Ver o texto de OLIVEIRA. O serviço público como técnica de proteção a direitos. Revista da Faculdade de Direito UFJF, p. 145-154.
}

A\&C R. de Dir. Administrativo \& Constitucional, Belo Horizonte, ano 8, n. 33, p. 91-113, jul./set. 2008 
comportamental dos poderes estatais, de um lado tendo o Poder Executivo, de forma arbitrária e concentrada, exercido o governo, tomando de assalto a máquina estatal para com ela levar a cabo políticas de gestão casuístas e comprometidas com universos segmentados do tecido social (em regra, os mais abastados). Para tanto, utiliza os instrumentos que o sistema jurídico lhe proporciona, como, no caso brasileiro, as Medidas Provisórias, o Orçamento Público, as trocas de favor com o Legislativo, as pressões simbólicas e reais de verbas e recursos para o Judiciário, etc. ${ }^{15}$ Com isto, vai gerando um insulamento institucional, o que lhe garante espaço e condições para governar sozinho, como detentor da onisciência capaz de identificar o que efetivamente a população necessita para seu cotidiano, numa franca relação, ou paternalista/assistencialista, em que o dolo para a provocação do mal e da corrupção vem diminuído (como no caso dos governos populistas), ou burocrática-autoritária, fundada nos permissivos normativos que autorizam comportamentos administrativos oriundos exclusivamente da autoridade competente, senhora de todas as coisas e de todos os homens, situação que facilita em muito a livre corrupção e os desvios da finalidade pública. ${ }^{16}$

O Poder Legislativo, por sua vez, tem perdido suas feições legiferantes, tanto em face da ação indutora e casuísta do Estado BurocráticoAdministrador, autor do maior número de iniciativas legislativas nos regimes presidencialista e mesmo parlamentarista, como em razão da perda de identidade social decorrente de sua acomodação institucional e dos altos índices de corrupção em que por vezes se vê acometido. Soma-se a isto o fato de que, por vezes, os representantes políticos da Democracia Representativa usam seus mandatos, ora sem a menor noção de República e Federação, presos às noções e preocupações locais e, no máximo, regionais, olvidando-se da inserção nacional e internacional que representa sua legislatura, ora como verdadeira mercadoria de troca e de barganha comercial ou financeira, atendendo a demandas pessoais e corporativas, todas dissociadas dos vínculos políticos matriciais que informam seu mandato. ${ }^{17}$

Por fim, no que tange ao Poder Judiciário, a despeito de que seu posicionamento face à realidade social não tem sido objeto de estudos jurídicos mais sistematizados, especialmente porque a matéria se enquadra

\footnotetext{
15 Ver o texto de SANTOS. Reinventar a democracia, p. 34 et seq.

${ }^{16}$ Conforme sinaliza o texto de MANIN. The principles of representative government, p. 92 et seq.

17 Ver o excelente texto de FUNG. Deepening Democracy, p. 29 et seq.
}

A\&C R. de Dir. Administrativo \& Constitucional, Belo Horizonte, ano 8, n. 33, p. 91-113, jul./set. 2008 
no âmbito da sociologia jurídica, em tese, entre nós pouco desenvolvida, podemos afirmar que ele também passa por, no mínimo, duas crises institucionais: (1) uma crise de identidade, principalmente em face da profunda anomia de responsabilidade pelos cenários que vimos anteriormente, já que nenhum dos poderes oficiais pretende assumir sua parcela no latifúndio caótico em que se vê imerso o tecido social. Assim, recaem sobre o Estado Juiz reclames os mais diversos e polêmicos possíveis, buscando-o como tábua de salvação de uma cidadania desterrada. (2) Uma outra crise é funcional e estrutural, já que a burocracia que o assola, não raro, o torna ineficiente, não conseguindo, sequer, cumprir com suas cotidianas tarefas operativas.

Em face disto é que o conceito de Estado Administrador não se confunde com a (e reduz à) instituição jurídica que toma corpo em seus poderes institucionais e passa por estas crises recém-referidas, mas é espaço de comunicação e explicitação de um mundo da vida ordenado por marcos normativos fundantes, vetores axiológicos positivos que estabelecem as regras do jogo democrático, a partir do qual se tem, tão-somente, um mínimo existencial assegurado, um plexo de prerrogativas e garantias que se postam como conquista histórica da humanidade em seu evolver. No mais, tudo pode e precisa ser construído, dependendo da capacidade criativa que se tem de superar as nossas próprias limitações, categoriais restritivas das possibilidades existenciais intersubjetivas que prometeu a racionalidade moderna.

Paralelo a isto estou convencido de que estes cenários todos desenhados evidenciam a necessidade de se resgatar algumas práticas do modelo de Estado de Bem-Estar Social, notadamente em países como o Brasil, em que o processo de crescimento econômico vai dissociado do desenvolvimento social. A função do Estado aqui, em face inclusive dos direitos fundamentais que deve assegurar, se faz mais necessária. Ou seja, políticas públicas de bem-estar inclusivo - necessárias ao cumprimento das prerrogativas do constitucionalismo social do século XX - implicam inevitavelmente uma maior presença de um Estado promovedor de ações afirmativas e compromissadas com toda a população, do que decorre sua presença mais forte e efetiva em setores estratégicos da economia, da educação, do trabalho, da assistência social, da saúde, da habitação, etc.

Ocorre que o modelo de economicismo neoliberal, o gerencialismo exagerado da Fazenda Pública voltado à redução do setor público de forma genérica e estrutural, sem avaliar previamente matérias e setores

A\&C R. de Dir. Administrativo \& Constitucional, Belo Horizonte, ano 8, n. 33, p. 91-113, jul./set. 2008 
concretos da cada realidade conjuntural, a busca da rentabilidade máxima, através de técnicas e mecanismos de racionalidade instrumental focada na lógica do custo-benefício do mercado, vão minando o Estado como gestor público coletivo, deixando espaço a interesses corporativos nacionais e internacionais.

O Brasil sofreu esta experiência com a reforma administrativa imposta pela Emenda Constitucional $n^{\circ} 19$, de 04.06.1998, impondo à Administração Pública a eficiência na gestão. O que ocorre é que a mesma emenda não mostrou quais os critérios e indicadores para aferir tal eficiência, mas, por certo, serão fornecidos pela iniciativa privada, com o explícito intento de instituir um discurso de fragilização ainda maior do Estado Administrador e justificar o projeto de privatização do espaço público.

Para as elites governistas deste país ao longo de sua história, entretanto, a posição sobre esta matéria é a de que:

Existe uma forte relação entre a falta de debate democrático nos países latinoamericanos e seu fracasso em alcançar e manter taxas de crescimento econômico maiores ou pelo menos iguais às dos países ricos. Falta-nos o espaço público, não apenas fisicamente - as ruas não são seguras, mas socialmente. Se na Sociedade brasileira houvesse maior "common ground", ou seja, um conjunto de valores e crenças e de regras do debate comuns, teríamos um melhor Estado e melhores governos. E nossos resultados no plano econômico e no social seriam bem melhores. ${ }^{18}$

Já que não há esse common ground, impõe-se, na perspectiva referida, ao invés do Estado e mesmo contra ele, garantir a setores estratégicos da economia nacional/internacional, não necessariamente produtivos, as condições necessárias para que a concentração de renda e lucros se perpetue, arcando com o custo social consectário.

Com o aumento daquela complexidade que referi e com a crescente diferenciação funcional da sociedade, é preciso constituir legítimas políticas públicas implementadoras dos vetores constitucionais e infraconstitucionais da ação estatal (e seus decorrentes serviços públicos), todos vinculados aos objetivos e finalidades estampadas no Título Primeiro da Carta Política de 1988. Nos dizeres de Antônio Medeiros:

O intervencionismo e a participação estão na raiz do fenômeno da "politização do social”, o que significa que a demarcação da linha imaginária entre Estado

\footnotetext{
${ }_{18}$ Conforme PEREIRA. A diferença está no debate. Folha de S.Paulo, São Paulo, 20 dez. 1999. Seção Opinião, p. $1-3$.
}

A\&C R. de Dir. Administrativo \& Constitucional, Belo Horizonte, ano 8, n. 33, p. 91-113, jul./set. 2008 
e Sociedade fica cada vez mais tênue como decorrência da privatização da esfera do público e da politização da esfera do privado. Assim, a análise de políticas públicas não necessariamente se refere apenas às políticas geradas nas instituições propriamente estatais, devendo também levar em conta as políticas geradas nas instituições não-propriamente estatais. Ou, como é mais freqüente, precisa referir-se às políticas geradas na imbricação da alavancagem propriamente estatal com alavancagem não-propriamente estatal. ${ }^{19}$

No Brasil o Estado tem respondido a estas demandas com altos índices de estatização da economia, com nível substancial de subsídios e financiamentos, com a contratação de serviços, produtos e obras, e com a tentativa de regulamentação do mercado. O efeito é, outra vez, o crescimento da burocracia e, o que é mais importante, o crescimento mais que proporcional das despesas e investimentos públicos, gerando o problema da crise fiscal de que falei.

De qualquer sorte, a politização do social tem criado novas lógicas de ação coletiva no país, fomentando os atores sociais a operar mais segundo a lógica da autonomia da mobilização política, e menos segundo a lógica do clientelismo e do corporativismo, traços marcantes da história republicana nacional. Assim, se antes a mobilização e a participação políticas se davam preponderantemente a partir do Estado, com mecanismos e processos de cooptação política, agora elas tem se inserido significativamente também a partir da Sociedade, com mecanismos e processos de representação política, o que implica, diferentemente da privatização exacerbada e sem controle do público - o que também tem informado a chamada reforma do Estado brasileiro - , uma reflexão sobre se o que se precisa é mais Estado, ou um Estado melhor, focado na busca pela compatibilização entre desenvolvimento social e crescimento econômico.

Ocorre que a reforma que foi pensada na década de 1990, anteriormente referida, esteve centrada na idéia de mudança do paradigma burocrático para o gerencial, em que, nas palavras de um dos seus principais mentores:

A reforma provavelmente significará reduzir o Estado, limitar suas funções como produtor de bens e serviços e, em menor extensão, como regulador, mas implicará ampliar suas funções no financiamento de atividades que envolvam externalidades ou direitos humanos básicos e na promoção da competitividade internacional das indústrias locais...

\footnotetext{
${ }^{19}$ MEDEIROS. Em busca de paradigmas para a análise de políticas públicas. Revista de Administração Pública, Rio de Janeiro, 10, 2, 241-256, p. 06, abr./jun. 1976.
}

A\&C R. de Dir. Administrativo \& Constitucional, Belo Horizonte, ano 8, n. 33, p. 91-113, jul./set. 2008 
Os cidadãos exigem do Estado muito mais do que o Estado pode oferecer. E a causa imediata da lacuna que assim se cria não é apenas fiscal, como observou O’Cornor (1973), nem apenas política, como Huntington (1968) destacou; é também administrativa. ${ }^{20}$

Todos estes fatores estão a exigir a revisão dos paradigmas que informam, classicamente, o problema da Administração Pública (reduzida a aspectos técnico-burocráticos de competência exclusiva do aparelho estatal) ${ }^{21}$ e sua relação com a sociedade.

\section{Qual o papel da cidadania em face dos serviços públicos?}

Estou sustentando aqui que a deliberação pública, realizada também e fundamentalmente fora do âmbito estatal, constitui a base de legitimação para a ação política. Este espaço, ao menos em termos hipotéticos, permitiria a todos os potencialmente envolvidos poder opinar e interagir comunicativamente antes que uma decisão fosse adotada. Desta forma, a livre circulação da informação e o alongamento das oportunidades educativas erigir-se-iam em elementos nodais que explicariam a aparição desta esfera de autonomia, tendo como motivação a implementação de condições histórico-sociais que possibilitariam a emergência, expansão e transformação de uma esfera pública efetivamente democrática. ${ }^{22}$

A partir de tais reflexões, o processo deliberativo levaria os cidadãos a terem de justificar suas decisões e opiniões apelando, em alguma medida, a interesses comuns, argumentando com proposições assertóricas que todos pudessem aceitar no debate público, a partir do espaço efetivo que possuem para discordar. Em outras palavras, uma decisão coletiva — como a que envolve questões atinentes à formatação, execução, qualidade, modicidade de tarifas e avaliação de serviços públicos — sobreviria, tão-somente,

\footnotetext{
20 PEREIRA; SPINK. Reforma do Estado e administração pública gerencial, p. 23.

21 A teoria mais tradicional do Direito Administrativo tem insistido na idéia de que ele serve, fundamentalmente, às atividades estatais (executivas, legislativas e judiciais) e de governo. De uma maneira mais sofisticada, trabalhando com conceitos múltiplos, por exemplo, Augustín Gordillo, em seu Tratado de Derecho Administrativo, insiste na concepção de que o Direito Administrativo (ou a função administrativa) diz respeito, fundamentalmente, às ações estatais tradicionais. No Brasil, Diogo de Figueiredo Moreira Neto, em sua obra Curso de direito administrativo, p. 04, é taxativo em afirmar que: é comum, por isso, num primeiro vis/umbre sobre o Direito Administrativo, conotá-lo principalmente às regras de funcionamento do Estado, enquanto que o Direito Constitucional seria, precipuamente, a disciplina das regras de sua estruturação. Assim, de uma certa forma, o conceito de gestão pública tem-se sintetizado como um conjunto harmônico e sistêmico de princípios jurídicos que regem os órgãos, os agentes e as atividades públicas tendentes a realizar concreta, direta e imediatamente os fins desejados pelo Estado. Nesse particular, há uma reflexão de FREITAS. A interpretação sistemática do direito.

22 HABERMAS, Jürgen. Mudança Estrutural da Esfera Pública. Rio de Janeiro: Civilização Brasileira, $1988, p$. 39. No mesmo sentido, ver o texto de BOHMAN, James. Public Deliberation: Pluralism, Complexity, and Democracy. Boston: Madinson, 2002. p. 13.
}

A\&C R. de Dir. Administrativo \& Constitucional, Belo Horizonte, ano 8, n. 33, p. 91-113, jul./set. 2008 
a partir de sua justificação por meio de razões públicas, expostas ao tensionamento da crítica e do falseamento. ${ }^{23}$

Neste modelo de deliberação, fundada na premissa de melhor formação e informação socialmente construída, a condição de cidadania restaria mais preparada para a adoção de decisões relevantes, isto em face do modelo tradicional de representação política institucional moderna, em que os espaços de discussão, deliberação e execução, ocorrem mediados por instrumentos e mecanismos por vezes artificiais, em termos de identidade e presentação social.

Os indivíduos que participam de um processo deliberativo, a partir da proposição que se está apresentando, em tese, teriam potencializadas as suas percepções sobre o que efetivamente querem, quais são realmente os seus desejos e objetivos; perceberiam, com maior nitidez, suas preferências antes de chegarem à instância de terem de tomar uma decisão ou escolher uma política concreta de vida e gestão. ${ }^{24}$

Então, através do processo de filtragem de preferências que resulta do debate público - entre atores públicos —, o número de opções viáveis se reduziria, porém, sem empobrecê-los qualitativamente; a discussão aberta permitiria, simultaneamente, enriquecer em potencial a gama e o conteúdo das opções e, por sua vez, delimitaria, de forma mais pontual, o espectro àquelas que se tornariam aceitáveis para o conjunto de participantes.

Destarte, a forma de gestão pública comunicativa que estou propondo ao novo modelo de Estado - e de serviços públicos — exige um mínimo de condições subjetivas e objetivas dos seus interlocutores, sob pena de as falas enunciadas e trocadas serem coatadas por circunstâncias exógenas e endógenas à comunicação, tais como as insuficiências formativas e de discernimento dos homens comuns do povo, associada com o alto grau de profissionalismo e burocratismo das elites dominantes que assaltaram o Estado, ou, ainda, dos tecnoburocratas que instrumentalizaram ideológica

\footnotetext{
23 HABERMAS. Mudança estrutural da esfera pública, op. cit., p. 188. Por certo que a necessidade de alcançar um compromisso - única maneira de atingir racionalmente um convívio societal emancipador — forçaria cada participante a encaminhar suas propostas sobre a rubrica de princípios gerais ou considerações políticas que os outros pudessem aceitar/discordar. Ver igualmente o texto de COOKE. Language and reason: a study of Haberma's pragmatics, p. 82.

${ }^{24}$ A partir da dinâmica do processo, as posições podem e invariavelmente mudam, revisam-se; a renegociação e a reespecificação tornam-se uma constante. As razões, ao serem testadas pelo enfrentamento e debate público, podem reformular-se, desde que fundadas em níveis cognitivos de compreensão e reflexão autônomos. De outro lado, esta experiência pode ter também um efeito transformador das crenças e opiniões destes participantes, e assim podem produzir-se melhores decisões públicas, no sentido de serem refratárias das demandas da maior parte quantitativa da população atingida. Ver o texto de HABERMAS. On the pragmatics of social interaction, p. 23.
}

A\&C R. de Dir. Administrativo \& Constitucional, Belo Horizonte, ano 8, n. 33, p. 91-113, jul./set. 2008 
e operacionalmente os aparelhos estatais, como mecanismo de alcançar projetos muito mais corporativos e individuais do que comunitários (como já referi anteriormente).

Onde se fizer ausente a capacidade de manifestação da vontade do cidadão como artífice de sua própria história, em face de sua insipiência política e administrativa, material e subjetiva, falecendo-lhe forças e perspectivas sobre os termos e possibilidades de gestão que circunvizinham seu cotidiano, só se reforça a situação de anomia societal no âmbito do poder institucionalizado e de seu exercício, em todas as suas dimensões (legislativa, executiva e jurisdicional), fortificando, por ato reflexo ou convexo, a situação confortante dos encastelados nas hordas do Estado Soberano. Decorrência disto é que, mesmo naquelas circunstâncias em que há uma previsão formal de participação política, ela não é exercitada material e eficazmente por estar marcada pela manipulação e esvaziamento provocado pela ausência daquelas condições mínimas necessárias à comunicação e entendimento.

É verdade que o Estado Social na Europa e em outros países da OCDE (Organização para a Cooperação e Desenvolvimento Econômico) compensou, da segunda metade do século XX em diante e em grande parte, as conseqüências indesejadas de um sistema econômico altamente produtivo, porém, desequilibrador das relações sociais, tendo o capitalismo possibilitado que se cumprisse a promessa republicana da inclusão igualitária de todos os cidadãos, contando, dentre outras coisas, com uma nova dicção normativa institucional-constitucional.

De fato, o Estado constitucional democrático garante a igualdade também no sentido de que todos devem ter a mesma oportunidade de fazer uso de seus direitos. John Rawls, hoje o teórico mais influente do liberalismo político, fala nesse sentido do "fair value" de direitos repartidos com paridade. Em vista dos desabrigados, que se multiplicam em silêncio sob nossos olhos, vem à memória a frase de Anatole France: não é suficiente que todos tenham o mesmo direito de "dormir sob as pontes". Quando compreendemos o texto de nossas Constituições nesse sentido material da realização de uma sociedade socialmente justa, a idéia da autolegislação, segundo a qual os destinatários das leis devem ser entendidos ao mesmo tempo como seus autores, ganha a dimensão política de uma sociedade que atua sobre si mesma. ${ }^{25}$

Como se viu, este modelo de Estado Social (e Nacional), no contexto modificado da economia e da sociedade mundiais, já no final da década

\footnotetext{
25 HABERMAS, Jürgen. Nos limites do Estado. Folha de S.Paulo, São Paulo, jul. 1999. Edição Especial, Caderno MAIS!, p. 4
}

A\&C R. de Dir. Administrativo \& Constitucional, Belo Horizonte, ano 8, n. 33, p. 91-113, jul./set. 2008 
de 1990, notadamente na Europa Central, chega aos limites de sua eficiência, ${ }^{26}$ põe-se em xeque com essa forma organizacional da economia e dos mercados, submetendo-se à domesticação política de um capitalismo global desenfreado, o que gera o funcionamento ficcional da democracia representativa e seus mecanismos de operação política, haja vista sua perda de comando nacional de gestor público soberano, dependendo, em verdade, de múltiplas variáveis que não estão mais sob seu controle e manipulação.

Vale, aqui, a advertência feita por Alba Zaluar, no sentido de que a crise financeira do Estado Providência, nos países economicamente independentes, reacendeu a preocupação com aquela parcela da população inativa, e mesmo ativa, que desenvolveu um certo vício da dependência estatal, tornando-se parasitas dos demais, ${ }^{27}$ destacando-se a necessidade de ser repensado o tema da responsabilidade social de todos os cidadãos.

A proposta é, então, que o Estado Passivo Providência seja substituído pelo Estado Ativo Providência. Não haveria mais assistidos a socorrer, mas pessoas com diferentes utilidades sociais, cuja capacidade deveria ser aproveitada. Nele também a socialização radical dos bens e das responsabilidades. Uma nova concepção de solidariedade é mobilizada na ideologia desse Estado: não é nem a caridade privada, nem o bem-estar advindo dos direitos sociais, nem a mutualidade do solidarismo do século XX. (...) as políticas públicas deveriam se ocupar de previnir a exclusão mais do que de reinserir os excluídos; de criar uma sociabilidade positiva mais do que de remediar a negativa, embora no quadro da crise atual o oposto tenha que ocorrer na política de reinserção. Os atores desse projeto seriam diferentes: não mais os sindicatos e o Estado redistribuidor, mas uma série de associações de diversos tipos, junto às quais o Estado ainda seria o principal ator do social, criando nova legitimidade para sua intervenção. ${ }^{28}$

Bell lembra que decorre deste cenário um problema de ajuste entre expectativas e realidade social, na medida em que as primeiras crescem em espiral, enquanto que a capacidade do Estado para atendê-las é cada vez mais limitada, produzindo uma explosión de las demandas y un implosión de los recursos ${ }^{29}$ Diante deste quadro de profundas demandas — quantitativa e qualitativamente - e recursos escassos, o foco de analistas, de políticos e da própria sociedade civil organizada (principalmente na Europa Central)

\footnotetext{
${ }^{26}$ Ocorrendo o que Bulmer chama de Welfare Backlash, in BULMER. The Goals of Social Policy, p. 92.

27 ZALUAR. Exclusão e políticas públicas: dilemas teóricos e alternativas políticas. Revista Brasileira de Ciências Sociais, p. 30.

28 ZALUAR. Op. cit., p. 32.

29 BELL. Las Contradicciones Culturales del Capitalismo, p. 119.
}

A\&C R. de Dir. Administrativo \& Constitucional, Belo Horizonte, ano 8, n. 33, p. 91-113, jul./set. 2008 
tem se voltado para o tema da gestão de interesses e recursos, evidenciando que o princípio da equidade que deve informar qualquer política pública de bem-estar deva ser combinado com os princípios da eficácia e da eficiência da prestação/ação estatal.

Em recente pesquisa na Espanha - o que retrata um pouco a realidade do século XX em termos de cidadania constitucional —, Jaime informa que os cidadãos espanhóis têm se tornado mais exigentes no que tange à avaliação da gestão pública em geral, gerando uma opinião pública mais crítica dos serviços prestados pelo Estado, o que vem operando efeitos diretos sobre a valoração das próprias instituições públicas, as quais não são julgadas mais tanto em termos ideológicos, mas em face de sua capacidade para gestar e resolver demandas sociais cotidianas. ${ }^{30}$

Se o Brasil não teve nenhuma experiência mais significativa de Estado Social de Direito, eis que marcadas as suas ações sociais por altos índices de clientelismo, assistencialismo e populismo alienantes, precisa aprender com a história recente do fracasso daquele modelo centrado somente nas instituições oficiais, para criar o seu próprio caminho, forjado na participação e co-gestão de interesses e demandas comunitárias. ${ }^{31}$

Por tais razões é que proponho que a formatação de políticas públicas e ações materiais conseqüentes envolvendo qualquer comportamento estatal, e mais especialmente serviços públicos, precisa se pautar, no mínimo, por alguns pressupostos básicos, a saber: (a) observar os vetores axiológicos universais e não metafísicos, como os direitos humanos e fundamentais, e os demais, estabelecidos pela ordem constitucional vigente; (b) recepcionar e problematizar, de forma permanentemente aberta e crítica, as proposições assertóricas de todos os atores sociais que se encontram sob sua égide, notadamente os que são atingidos, direta ou indiretamente, pelas ações estatais sob comento, numa perspectiva de entendimento e consenso, consciente da natureza tensional de tal tarefa; (c) explicitar os argumentos de justificação e fundamentação que pretendem legitimar os modelos de

\footnotetext{
30 JAIME. Las actitudes de los españoles hacia las políticas sociales. Revista Internacional de Sociologia, p. 48. Num quadro estatístico muito rico, Jaime conclui que o apoio social às políticas sociais tem se mantido muito estável tanto na Europa Central, como nos EUA, isto desde a década de 1970. Tudo isto contribuiu naquele final de século XX para uma reformulação no conceito do Estado, ainda de Bem-Estar Social, explodindo de um lado com seus recursos institucionais, e politizando em alguns aspectos (porque alienando em outros) uma cidadania constitucional que se vem firmando no Ocidente.

31 Não se pode esquecer aqui que a Administração Pública no Brasil, assim como na maior parte dos países da América Latina, tem se pautado pela profunda indiferença em relação às aspirações e reais demandas da comunidade alcançada por suas práticas oficiosas, gerida por corporações que se apoderam do Estado e o transformam em aparelho ou instrumento de seus interesses privados.
}

A\&C R. de Dir. Administrativo \& Constitucional, Belo Horizonte, ano 8, n. 33, p. 91-113, jul./set. 2008 
concepção, organização, execução e avaliação, estatal e social, das políticas públicas e das ações concretizantes atinentes às demandas comunitárias.

É inexorável, por outro lado, romper-se o argumento de que o tema da administração pública possui um grau de complexidade e especificidade que vão desde sua dimensão gramatical/lingüística até a sua operacionalização, eis que conta com um universo categorial tão próprio e pontual que só é alcançado pelos já iniciados em sua ciência, deixando os incautos cidadãos comuns do povo sem compreensão dos seus enunciados e discursos, o que inviabiliza, por conseqüência, a compreensão de suas práticas, eis que decorrência da operacionalização daqueles conceitos e discursos. Em tal cenário, o que resta à sociedade é, tão-somente, avaliar os resultados das ações e políticas públicas, sendo-lhe vedado o atingimento dos níveis de discussão e deliberação sobre a concepção/eleição daquelas ações e políticas - questões restritas às instituições competentes. ${ }^{32}$

Ledo engano, a uma, porque estas teses partem de pressupostos equivocados e ultrapassados, quais sejam, de que somente os mecanismos e instrumentos da democracia representativa (voto, partidos políticos, parlamento, etc.) é que têm a competência e legitimidade exclusiva à representação dos interesses sociais; a duas, o fato de que a sociedade civil contemporânea não consegue se articular/mobilizar em torno de suas demandas, a ponto de veicular propostas, ações e cobranças eficazes em termos de gestão da coisa pública; a três, porque faltam aos atores sociais hodiernos condições mínimas de compreensão dos atos da administração pública.

Afigura-se igualmente frágil o argumento de que um excesso de participação da sociedade acarretaria desgaste às formas clássicas de representação política da democracia moderna, isto porque não são incompatíveis com os novos sujeitos sociais que são os grupos mobilizados de determinados setores da comunidade. Se for verdade que tais movimentos apresentam perfis organizacionais próprios, inserção específica na tessitura social e articulações particulares com o arcabouço de poder existente, não é menos real que eles também necessitam da esfera pública e institucional do debate de temas que lhes dizem respeito (por exemplo, dialogando com o Estado para obter dele demandas que lhes afligem).

Com já referi em outra oportunidade, ${ }^{33}$ é plenamente possível, em

\footnotetext{
32 Ver a título exemplificativo o texto de BOVERO. Una grammatica della democrazia, p. 137 et seq.

33 LEAL, Rogério Gesta. Estado, Administração Pública e sociedade: novos paradigmas. Porto Alegre: Livr. do Advogado, 2006. Ver também o trabalho de FINGER. Serviço público: um instrumento de concretização de direitos fundamentais. Revista de Direito Administrativo, p. 59-82.
}

A\&C R. de Dir. Administrativo \& Constitucional, Belo Horizonte, ano 8, n. 33, p. 91-113, jul./set. 2008 
face de tal quadro - e até necessário - imaginar situações de cooperação entre Partidos Políticos, Parlamento, Poder Executivo e Movimentos Sociais organizados, eis que todos possuem, ao menos em tese, o mesmo móvel e objetivos: o interesse público — sempre tensional e conflituoso. ${ }^{34}$ A instância formal de representação comunitária pode e deve instituir um espaço permanente de interlocução com a instância informal de presentação desta mesma comunidade, e deles todos com o Estado Administrador.

\section{A formatação dos serviços públicos como resultado da inter- locução entre Estado e sociedade}

Qualquer Administração Pública para se configurar como democrática e comunicativa precisa, em face do ponderado até aqui, contar/construir o maior número possível de adesão social legítima, adquirida através de ações comunicativas eficazes, com todos os agentes envolvidos e alcançados pelo exercício do poder político - institucionais ou não. Ao mesmo tempo, pelo fato de as ações administrativas cotidianas comportarem pretensões (de serviços públicos, por exemplo), sendo elas constituídas de verdades proposicionais, fundadas em correções normativas, e veracidades subjetivas, devem satisfazer um requisito essencial: serem suscetíveis de fundamentação e crítica constantes, retroalimentadoras do controle e depuração social.

Por outro lado, não tenho dúvidas (com Habermas) ${ }^{35}$ do caráter precário e contingencial do entendimento e do acordo conseqüente buscado/ atingido por esta Administração Pública Comunicativa com o povo soberano (cidadania/usuários de serviços públicos), aqui concebida como um processo, através de procedimentos, pois os êxitos consensuais para ações públicas pontuais nem sempre conduzem a cenários absolutamente estáveis, pelo contrário,

a estabilidade e a univocidade são mais a exceção na prática comunicativa cotidiana. Mais realista é a imagem que nos oferece a etnometodologia de uma comunicação difusa, frágil, constantemente submetida a revisão e só lograda por alguns instantes, em que os implicados se baseiam em pressuposições

\footnotetext{
34 Principalmente diante de um quadro político em que apenas a dimensão econômica dos direitos civis e sociais é parcamente assegurada, isto porque eles são introduzidos pelo Estado e no Estado para facilitar a institucionalização de um modelo de mercado e relações de produção. Neste sentido, ver o texto de AVRITZER. Cultura política, atores sociais e democratização: uma crítica às teorias da transição para a democracia. Revista Brasileira de Ciências Sociais, p. 115.

35 Ver HABERMAS. Strukturwandel der Öffentlichkeit, p. 49 et seq.
}

A\&C R. de Dir. Administrativo \& Constitucional, Belo Horizonte, ano 8, n. 33, p. 91-113, jul./set. 2008 
problemáticas e não declaradas, sempre movendo-se por tentativas desde logo naquilo que estão de acordo, para o seguinte. ${ }^{36}$

Isto se explica pelo simples fato do reconhecimento da complexidade que marca as relações sociais contemporâneas, sempre em permanente mutação e ampliação de suas demandas e conflitos. Porém, o que se busca na Administração Púbica (e no serviço público) e com ela é a garantia de um espaço público de enfrentamento de todas as particularidades deste cenário, acolhendo a diversidade e a diferença como elementos imprescindíveis para o debate, a deliberação e a execução das políticas públicas norteadoras das ações voltadas à comunidade como um corpo político orgânico e ativo. É este plano de visibilidade plena e plana que deve marcar o novo modelo de gestão pública compartida, criando as condições objetivas e subjetivas para que a participação política da cidadania seja condição de possibilidade da Administração Pública Democrática de Direito.

Esta gestão pública compartida encontra-se, pois, alicerçada numa nova racionalidade gerencial, fundada nos direitos humanos e na noção de soberania popular, enquanto substância ética de uma determinada comunidade política, ao mesmo tempo que remete para the rules of discourse and forms of argumentation that borrow their normative content from the validity basis of action oriented to reaching understanding. ${ }^{37}$

Veja-se que é a própria dicção da Carta Política brasileira de 1988 que induz à concretização de seus comandos a existência de uma cidadania orgânica e não letárgica, uma cidadania que, antes de consumidora de serviços prontos e acabados, constitui a condição e possibilidade do espaço público, e, por isso, apresenta-se como co-responsável (solidariamente) pela definição de que Estados, serviços e políticas públicas são necessários, visando o atendimento não de interesses moleculares e subjetivos dos atores societais, mas daquilo que interessa à maior parte quantitativa dos que são ou não alcançados por tais comportamentos.

Aqui se têm, ao menos, duas metodologias de procedimentos que podem ser adotadas visando à concretização daquelas pautas normativas constitucionais (e infraconstitucionais), a saber: a descentralização da gestão propriamente dita e a delegação do poder de gestão.

\footnotetext{
${ }^{36}$ ARAGÃO. Razão comunicativa e teoria social crítica em Jürgen Habermas, p. 29.

37 HABERMAS. Historical Consciousness and Post-Traditional Identity: Remarks on the Federal Republic's Orientation to the West. Acta Sociologica, p. 86.
} 
Para Keeler, a delegação de poder e a descentralização estão intimamente ligadas, tanto na teoria quanto na prática. Porém, são bem diferentes, uma vez que a delegação de poder diz respeito a quem cabe a responsabilidade pelas decisões, enquanto que a descentralização diz respeito a quem as executa. Pode haver delegação de poder sem descentralização de funções. ${ }^{38}$

O argumento para adotar a delegação e a descentralização de poder é claro: a autoridade estatal, para tomar decisões administrativas, tradicionalmente, esteve concentrada nos níveis mais altos da administração. A função da descentralização e da delegação de poder deve potencializar as práticas administrativas para uma abertura de participação em todos os seus níveis. Se o objetivo é deixar (ou fazer) os administradores e administrados administrarem, eles devem ter autoridade para fazê-lo. Em outras palavras, a partir do cânone da delegação, administradores e administrados passam a ter maior autonomia para decidir, mas, ao mesmo tempo, passam a ter de prestar contas (mediante as avaliações de desempenho) pelo exercício desta autoridade. Em relação à desconcentração da gestão, outras ambiências precisam ser criadas no sentido de trazer à administração dos interesses coletivos o maior número de interessados e atingidos por ela.

Assim, se de um lado conta-se com previsões normativas que dão ensejo às teses aqui levantadas da participação popular na gestão pública do cotidiano, de outro também se conta, ao menos hoje, com as mesmas previsões demarcando possibilidades materiais de instrumentos e mecanismos para tal participação. Veja-se que, neste novo modelo experimental de Estado e Sociedade Civil, a função do primeiro não é só garantir a igualdade de oportunidades aos diferentes projetos de institucionalidade democrática, mas também garantir padrões mínimos de inclusão que tornem possível, à cidadania ativa, criar, monitorar, acompanhar e avaliar o desempenho dos projetos de governo e proteção da comunidade. Esses padrões mínimos de inclusão são indispensáveis para transformar a instabilidade institucional em campo de deliberação democrática. ${ }^{39}$

Em face das profundas desigualdades regionais existentes no território brasileiro, de diversas matizes, a função do Estado ganha relevo sim, não a ponto de substituir ou dispensar o corpo político da soberania

\footnotetext{
38 KEELER. Opening the window for reform: mandates, crises, and extraordinary decision-making. Review of Compararive Politicial Studies, p. 433-86.

${ }^{39}$ Ver o texto de AVRITZER. Teoria democrática, esfera pública e participação local. Revista Sociologias, p. 18-43.
}

A\&C R. de Dir. Administrativo \& Constitucional, Belo Horizonte, ano 8, n. 33, p. 91-113, jul./set. 2008 
popular - pelo contrário -, mas de ser protagonista destacado em políticas públicas de inclusão social e ações concretizadoras de direitos fundamentais. Para tanto, impõe-se a ele uma certa iniciativa à gestão de interesses coletivos, notadamente no âmbito da prestação de serviços, indo além da tradicional função de Estado Gendarme, respondendo pela mantença da ordem estabelecida, e passando a produzir e redistribuir (consorciadamente) o bem-estar à sua cidadania.

Quero com isto dizer que não posso aceitar a tese de que uma modalidade de Estado Social, a despeito de representar uma norma fim-deEstado que fixa, de maneira obrigatória, as tarefas e a direção da atuação estatal presente e futura, não cria, por conseqüência, direitos subjetivos para a sua realização, ${ }^{40}$ eis que tais compreensões de Estado e de Administração estariam por esvaziar, ao fim e ao cabo, os próprios direitos fundamentais referidos. Da mesma forma é certo que muitas normas constitucionais programáticas sobre direitos sociais, por não possuírem um mínimo de condições para sua efetivação, serviram e até têm servido como álibi para criar a imagem de um Estado que responde normativamente aos problemas reais da sociedade, desempenhando, assim, uma função preponderantemente ideológica em constituir uma forma de manipulação em que há uma ilusão que imuniza o sistema político contra outras alternativas. ${ }^{41}$

Enfim, dialogando com Canotilho, quero crer que o serviço público no Estado Democrático de Direito contemporâneo precisa estar fundado em um constitucionalismo moralmente reflexivo, optando por modelos regulativos típicos da subsidiariedade, de autodireção social estatalmente garantida, ${ }^{42}$ forma mais includente de empoderamento social e responsividade coletiva.

\section{Referências}

ALEMÁN, Carlos. Fundamentos de Bienestar Social. Valencia: Tirant lo Blanch, 2004.

ARAGÃO, Lucia Maria de Carvalho. Razão comunicativa e teoria social crítica em Jürgen Habermas. Rio de Janeiro: Tempo Brasileiro, 1992.

ASHFORD, Daniel Ernandéz. La aparición de los Estados de Bienestar. Madrid: Ministerio de Trabajo y Seguridad Social, 2001.

\footnotetext{
40 Conforme quer KRELL. Realização dos direitos fundamentais sociais mediante controle judicial da prestação dos serviços públicos básicos (uma visão comparativa), op. cit., p. 245.

${ }^{41}$ Ver o excelente trabalho de NEVES. Do consenso ao dissenso: o Estado Democrático de Direito a partir e além de Habermas. In: SOUZA. Democracia hoje, p. 111.

42 CANOTILHO. Estado de direito, p. 62. Discordo, todavia, quando o autor português nega a possibilidade da geração de direitos subjetivos na base de direitos constitucionais sociais, alegando que somente o legislador ordinário seria legitimado a determinar o conteúdo concreto dos direitos sociais, sem vinculação estrita às normas programáticas da Constituição, pelas mesmas razões acima referidas.
}

A\&C R. de Dir. Administrativo \& Constitucional, Belo Horizonte, ano 8, n. 33, p. 91-113, jul./set. 2008 
AVRITZER, Leonardo. Cultura política, atores sociais e democratização: uma crítica às teorias da transição para a democracia. Revista Brasileira de Ciências Sociais, São Paulo, ano 10, n. 28, 1995.

AVRITZER, Leonardo. Teoria democrática, esfera pública e participação local. Revista Sociologias, Porto Alegre, ano 1, n. 2, jul./dez. 1999.

BECK, Urlich. Vivir nuestra propria vida en un mundo desbocado: individuación, globalización y política. In: GIDDENS, Antony; HUTTON, Wladimir. En el límite: la vida en el capitalismo global. Barcelona: Tusquets, 2001.

BELL, Daniel. Las Contradicciones Culturales del Capitalismo. Madrid: Alianza, 2006.

BOHMAN, James. Public Deliberation: Pluralism, Complexity, and Democracy. Boston: Madinson, 2002.

BOVERO, Michelangelo. Una grammatica della democrazia. Millano: Trotta, 2002.

BULMER, Martin. The Goals of Social Policy. London: Unwin Hyman, 2007.

CACHÓN, Luiz. Estado de Bienestar y Capitalismo Avanzado. Madrid: Alianza, 2002.

CANOTILHO, J. J. Gomes. Estado de direito. Lisboa: Gradiva, 1999.

COOKE, Maeve. Language and reason: a study of Haberma's pragmatics. Cambridge: MIT, 2000 .

DAHRENDORF, Ralph. Después de la Democracia. Barcelona: Critica, 2002.

DE LEONARDIS, Orlando. In un diverso Welfare: sogni ed incumbi. Milano: Feltrinelli, 2005 .

DUGUIT, Leon. Les Transformations du Droit Public. Paris: La Memoire du Droit, 1999.

FINGER, Ana Cláudia. Serviço público: um instrumento de concretização de direitos fundamentais. Revista de Direito Administrativo, Rio de Janeiro, 2003.

FREITAS, Juarez. A interpretação sistemática do direito. São Paulo: Malheiros, 1995.

FUNG, Norbert. Deepening Democracy. London: Verso Press, 2002.

GORDILlO, Augustín. Tratado de Derecho Administrativo. Buenos Aires: Fundación de Derecho Administrativo, 1998.

HABERMAS, Jürgen. Historical Consciousness and Post-Traditional Identity: Remarks on the Federal Republic's Orientation to the West. Acta Sociologica, New York, v. 31, 2006.

HABERMAS, Jürgen. Mudança estrutural da esfera pública. Rio de Janeiro: Civilização Brasileira, 1988.

HABERMAS, Jürgen. Nos limites do Estado. Folha de S.Paulo, São Paulo, jul. 1999. Edição Especial, Caderno MAIS!, p. 4-5.

HABERMAS, Jürgen. On the pragmatics of social interaction. Cambridge: MIT, 2002.

HABERMAS, Jürgen. Strukturwandel der Öffentlichkeit. Boon: Darmstadt, 1978.

HABERMAS, Jürgen. Teoria dell'agire comunicativo. Bologna: Il Mulino, 1986.

JAIME, Antonio Márquez. Las actitudes de los españoles hacia las políticas sociales. Revista Internacional de Sociologia, Madrid, v. 26, 2006.

A\&C R. de Dir. Administrativo \& Constitucional, Belo Horizonte, ano 8, n. 33, p. 91-113, jul./set. 2008 
KEELER, John Thomas. Opening the window for reform: mandates, crises, and extraordinary decision-making. Review of Compararive Politicial Studies, Pricepton, v. 25, p. 433-86, 1999.

KRELL, Andreas J. Controle judicial dos serviços públicos básicos na base dos direitos fundamentais sociais. Revista de Informação Legislativa, Brasília, out./dez. 1999.

KRELL, Andreas J. Realização dos direitos fundamentais sociais mediante controle judicial da prestação dos serviços públicos básicos (uma visão comparativa). Revista de Informação Legislativa, Brasília, out./dez. 1999.

LEAL, Rogério Gesta. A função social da cidade e da propriedade no Brasil. Porto Alegre: Livraria do Advogado, 1999.

MANIN, Bárbara. The principles of representative government. Cambridge: Cambridge University Press, 1999.

MEDEIROS, Antônio Carlos. Em busca de paradigmas para a análise de políticas públicas. Revista de Administração Pública, Rio de Janeiro, 10, 2, 241-256, p. 06, abr.jun. 1976.

MEIRELLES, Hely Lopes. Direito administrativo brasileiro. São Paulo: Malheiros, 2005.

MOREIRA NETO, Diogo de Figueiredo. Curso de direito administrativo. Rio de Janeiro: Forense, 1996.

NAVARRO, Vicente. Neoliberalismo y Estado del Bienestar. Barcelona: Ariel, 2004.

NEVES, Marcelo. Do consenso ao dissenso: o Estado Democrático de Direito a partir e além de Habermas. In: SOUZA, Jessé. Democracia hoje. Brasília: Ed. UnB, 2001.

OFFE, Clauss. Contradicciones en el Estado del Bienestar. Madrid: Alianza, 2001.

OLIVEIRA, Carlos Frederico Delage Junqueira de. O serviço público como técnica de proteção a direitos. Revista da Faculdade de Direito UFJF, Juiz de Fora, 2004.

PACI, Mauricio. Welfare State: chi há beneficitato dello Stato Sociale, a chi andrà la nuova solidarietà. Roma: Ediesse, 2007.

PEREIRA, Carlos Bresser. A diferença está no debate. Folha de S.Paulo, São Paulo, 20 dez. 1999. Seção Opinião, p. 1-3.

PEREIRA, Luiz Carlos Bresser; SPINK, Peter Kevin. Reforma do Estado e administração pública gerencial. Rio de Janeiro: Ed. FGV, 1999.

SANTOS, Boaventura de Sousa. Reinventar a democracia. Lisboa: Gradiva, 1999.

ZALUAR, Alba. Exclusão e políticas públicas: dilemas teóricos e alternativas políticas. Revista Brasileira de Ciências Sociais, São Paulo, v. 12, n. 35, out. 1997.

\footnotetext{
Informação bibliográfica deste texto, conforme a NBR 6023:2002 da Associação Brasileira de Normas Técnicas (ABNT):

LEAL, Rogério Gesta. Densificações democráticas do serviço público no Brasil: alguns pressupostos. A\&C Revista de Direito Administrativo \& Constitucional, Belo Horizonte, ano 8, n. 33, p. 91-113, jul./set. 2008.
}

A\&C R. de Dir. Administrativo \& Constitucional, Belo Horizonte, ano 8, n. 33, p. 91-113, jul./set. 2008 